\title{
El Cementerio Parroquial
}

\author{
-El Cementerio Parroquial, es un capifulo de .El \\ Juez Ruralı, novela de Pedro Prado cuya publicación \\ está próxima.
}

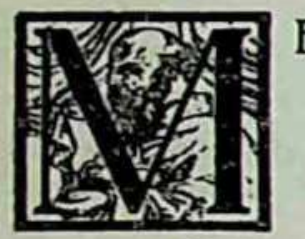

\section{La legua larga llenaron los picantes comentarios
La Tierra. \\ -Yo te lo advertí!}

-Quién va a pintar ahora. Sigamos...!

Y Mozarena tomó un aire enérgico y un paso decidido de grandes y recias zancadas, moviendo los brazos con un vaivén de amplia y contenida energía.

Solaguren cogido por un pasajero entusiasmo le imitó breves instantes pero. antes de poco, a ambos los volvió a coger el paso lento, desmadejado e insensible de los caminantes. - ¿Dónde estamos? - preguntó Solaguren asomándose sobre unos tapiales medio derruidos. ¿Qué cementerio es éste? ¿Cementerio?-Acudió el pintor, y trepó igualmente.

Era un potrerillo con los cierros caidos donde algunas vacas pastaban entre las tumbas.

Quisieron entrar, pero, en los portillos, defensas de alambres de púa, se mostraban peligrosas.

Rondando a lo largo de los cierros que sombreaban viejas encinas, dieron con un rancho medio abandonado y oculto entre los cardos y altas cicutas que crecían al arrimo de los desmigajados paredones.

Dos niños pequeños, pringosos los rostros, que jugaban con montoncitos de tierra, les quedaron mirando.

-Ehl chicos, ¿se puede entrar al cementerio?

Los niños inmóviles, sin responder, seguian observándoles.

- ¿No hay nadie en esta casa?

No se oía ruido alguno: el viento curioseaba por los rincones; parecía ser el dueño de aquella casa en abandono. Bajo un cobertizo sombrío contiguo a la casa, veianse unos ataudes viejos, despintados, opacos los barnices, las cruces y manillas comidas de orín, las tablas desastilladas, o medio podridas. 


\section{- ¿Entremos? -insinuó Mozarena consultando a su amigo.}

Los niños sentados en el polvo, sin levantarse de su sitio. les vieron pasar y torciendo la cabeza se contentaron en seguirles con la visfa.

Un patiecillo sombreado por acacios y restos de una reja de alambre con una puerta de débiles maderos, rota. remendada. e inútil, pretendian separar la casa del camposanto.

El cementerio estaba invadido por las hierbas. Dos vacas golosas echadas sobre las tumbas, dejaron de rumiar; alzándose sin prisa tomaron el camino de los portillos que daban hacia los potreros vecinos. Veíanse cruces quebradas y caidas, restos pisoteados de piadosos jardinillos con geranios sonrientes, rosales mustios, lánguidas campánulas y humildes nomeolvides.

Despedazadas las pequeñas rejas que rodeaban las fosas. los armazones de los ramos y coronas yacian dispersos por el suelo: sólo las flores secas y los pintarrajeados papeles que podía acarrear el viento, habian sido llevados por las ráfagas a un rincón del cementerio donde quedaban enredados entre renuevos de espinos. como en una fosa común de recuerdos y nostalgias.

Solaguren callaba con el rostro contraído en su clásico gesto de desprecio ante los casos oscuros.

Mozarena, curioso, seguía, lentamente, observándolo todo. -Qué cementeriol Toda cruz tiene dos nombres uno diverso por cada cara:

Isidro Zuleta

1873-1903

Amandina Heredia

1856-1903

leyó levantando una cruz caída. Dos para una cruz! La cruz enmedio, entre las cabeceras de ambas fosas. Rota, caída y arrastrada por las vacas hacia donde duerme la vieja Amandina o el pobre Zuleta.

Solaguren quiso hundir el mastil mayor de la cruz, pero la tierra, dura, no se dejó penetrar.

- ¿Qué hacer?-observó el pintor arrojando el madero.- ¿Cómo sabes dónde cae el uno. dónde el otro? Vas a dejarlos con los nombres cambiados...

Enseguida de las fosas venían tumbas de cal y ladrillo: pomposos y ridículos remedos de los mausoleos de Santiago, hechos por rústicos albañiles. Columnas débiles, sin fuste, desgarbadas, soportaban, inclinándose, frontones enormes, complicados y amenazantes, con ladrillos corridos. cruzados de grietas profundas. en las que arraigaban hierbas chamuscadas quebradizas y finas, como cadejos de cabellos tostados. Recios temblores habían dado cuenta, tiempo atrás, de muchas de ellas. Una imagen de Cristo se erguía entre los escombros. Una lagartija tomaba el sol en el cuello del Nazareno, y el destrozo que hicieran en su rostro y en su cuerpo el derrumbe de los muros. los colores impregnados de débiles mordientes que las lluvias mezclaron, hacian de el Hijo del Hombre un resucitado que pugnase por escapar de entre los muertos. 
Al lado de esa figura apocalíptica había una tumba extraña, y otra, y otras... que se le asemejaban. Parecian representar el último modelo adoptado.

Pequeñas techumbres de dos aguas cubrian profundas escavaciones hechas en la tierra. Entre las breves vigas y tijerales de los ligeros galpones, menudos. como pájaros que se hubiesen detenido un momento en la sombra, minúsculos ataúdes hacian pensar en párvulos inverosimiles.

Asomándose al borde de una escavación, divisaron, tallados en la gruesa tosca, varios nichos superpuestos con ataúdes a la vista. Nichos abiertos como celdas de un panal amargo y gigantesco, labrado en las entrañas de la tierra, y lleno aún de las Tatídicas larvas de la muerte.

-Buenos dias!

Una mujer, que traía de la mano a uno de los niños que vieran jugando a la entrada, se acercaba.

- ¿Usted vive aqui?-preguntó Solaguren.

- Si, señor.

- ¿Su marido es el sepulturero?

- Soy viuda; yo lo reemplazo.

-Ah! ¿es usted?

-Estaba enferma en el hospital cuando él murió. Nadie lué a avisarme. Tres meses estuve muriéndome. Cuando volví, hacia cuatro semanas que el finado estaba bajo tierra.

- ¿Y estos niños?

- Abandonados, señor; luego los recogió el señor cura.

- ¿Vive sola?

-Sola.

- ¿Este es el Cementerio de Barrrancas?

- Sí; el cementerio parroquial. Desde el terremoto no se levantan los cierros, y ya vé como están...

- Cuando llegamos había unas vacas...

-Es inútil echarlas: siempre vuelven. En la noche se pasan casi todas las de los potreros vecinos: les gusta dormir al abrigo de estos árboles. Yo ¿qué puedo hacer? Lo que cierro hoy, mañana está abierto! Una vez se cayó una vaca aquí dentro-dijo señalando una fosa.-Desde entonces puse ramas, alambres y lo que pude encontrar en torno de los galponcitos. ¡El trabajo que costó sacarla! Mozarena.

-Y ¿qué significan estos ataúdes tan pequeños entre las vigas?-preguntó

Son de niños-aseguró Solaguren.

- No, señor, son restos.

-Restos ¿de qué?

- Cuando pasa el tiempo, y de los finados sólo quedan unos pocos huesos, y los cajones aún están servibles, los saco y los pongo en estos chiquitos.

- Ahl dentonces esos ataudes que están cerca de su casa?...

- Sí; como no todos tienen dinero para comprar un cajón nuevo, los pobres compran de esos. 
Mozarena miró a Solaguren haciéndole un guiño; y la mueca que ya apuntara en el juez adquirió un relieve mayor.

- ¿De modo que tiene ese negocito, señora?-dijo el pintor.

-El pobre busca ayudarse... Enferma no he tenido tiempo de sacar los restos de un cajón que está afuera desde el día de San Andrés. ¿Quieren verlo? En un sendero vecino había atravesado un ataúd.

-Es de una señora de la hacienda de Coronel: murió hace bastante tiempo.

Palanqueando con un trozo de tabla que recogió de por alli cerca, logró desclavar la tapa del ataúd.

Mozarena y Solaguren se asomaron timidos y curiosos. como si se abriese ante ellos la boca de un abismo.

Sorprendidos por la luz unos coleópteros pequeños, corrieron escondiéndose bajo los retazos manchados y podridos de ligeras telas que cubrian a trechos el cadáver: telas reducidas a la urdiembre como redes de araña palpitantes en rincones abandonados. El viento curioso las fué palpando: las telas quemadas se deshicieron en polvo. Desnuda se ofreció la muerta a las miradas atónitas! iDesnuda aún de carnes! Hasta de la cabeza se habia despojado; rotos los tendones del cuello, deshecha la unión de las vértebras, una noche el cráneo debió rodar dentro del ataúd. Carcomidos los ligamentos de los dedos, un día los huesos de las falanjes, como cuentas de un rosario cuyo hilo se corta, debieron caer dispersas. Cruzadas sobre el pecho, las manos sin dedos, eran viejas flores deshojadas: El pecho hueco, el vientre hundido y roto... Ahí estaba la muerta desnudándose de todo su cuerpo! Era un viejo cadáver que olía como uno de esos rincones oscuros de los bosques, donde se pudren las hojas.

Solo una mazamorra grasienta que había derivado hacia los piés del ataúd. daba una impresión nauseabunda.

Mozarena salió del cementerio. Solaguren permanecia observando el cadáver; la sepulturera había cogido una rama y pasándola por una de las órbitas vacías, ensartó el cráneo distante para dejarlo en su sitio.

El sol al ocultarse tras las nubes que cubrian la cordillera de la costa. apresuró un crepúsculo largo y ceniciento.

Un fresco mayor comenzó a venir sobre los campos. Al llegar ambos amigos al camino de Valparaíso, ya obscurecía. Carretas cargadas de legumbres se dirigian a Santiago. Un tiempo marcharon al lado de ellas: pero pronto las antecedieron. Cuando dejaron de oír los chillidos de las ruedas y los broncos golpes que daban al cruzar los malos pasos, cerraba la oscuridad de la noche. Ante ellos el camino era algo sin término. De vez en cuando, sombras emergian: otros seres que cruzaban silenciosos... Y la vaga solidaridad que nace entre los viandantes, era desvanecida por la desconfianza que traen las tinieblas. 